\section{Plant Regeneration from Protoplasts Isolated from Embryogenic Callus of Satsuma}

\author{
Jing-Tian Ling, Nobumasa Nito, Masao Iwamasa, and \\ Hisato Kunitake \\ Faculty of Agriculture, Saga University, Saga 840, Japan \\ Additional index words. Citrus unshiu, adenine, somatic embryogenesis
}

\begin{abstract}
Embryos were obtained from unfertilized and undeveloped seeds of satsuma (Citrus unshiu Marc.) cultured on a modified Murashige and Tucker (MT) medium. Embryogenic callus was induced from the hypocotyl region of the embryos. The callus was successfully maintained through subculturing on MT medium with $185 \mu \mathrm{M}$ adenine, $2.8 \mu \mathrm{M} \mathrm{GA}_{3}$ and $400 \mathrm{mg}$ malt extract/liter, solidified with Gelrite. Somatic embryogenesis occurred from callus subculture on medium containing $50 \mathrm{~g}$ lactose/liter and in the absence of plant growth regulators. Somatic embryos developed into plants on medium with sucrose and $\mathbf{G A}_{3}$. Protoplasts isolated from this callus produced somatic embryos through colony formation: subsequently, normal, entire plants were regenerated.
\end{abstract}

Systems for somatic embryogenesis and plant regeneration from protoplasts have been developed in Citrus (Hidaka and Kajiura, 1988; Kobayashi et al., 1983; Kochba et al., 1972; Ling et al., 1989; Vardi et al., 1975; Vardi et al., 1982) and its related genus $\mathrm{Mi}$ crocitrus (Vardi et al., 1986). For the successful production of somatic hybrids by protoplasm fusion, embryogenic capacity of one of the partners is a prerequisite. Fused protoplasts can regenerate embryos and plantlets even though one of the partners lacks embryogenic capacity (Grosser et al., 1988a, 1988b; Kobayashi et al., 1988; Kobayashi and Ohgawara, 1988; Ohgawara et al., 1985; Vardi et al., 1987).

Satsumas are very important for the Citrus industry of Japan, and their improvement has been based on mutations and clonal selections (Iwamasa, 1983). Hybridization with satsumas has been difficult to achieve due to polyembryony and male sterility. If plant regeneration from protoplasts was possible, there would be new possibilities for satsuma breeding. Although mesophyll protoplasts of satsuma were used as one of partners for somatic hybridization (Kobayashi and Ohgawara, 1988; Kobayashi et al., 1988), we found no reports of plant regeneration from satsuma protoplasts. This paper deals with the establishment of embryogenic callus and plant regeneration from callus protoplasts in satsuma cultivars.

Mature fruits from open-pollinated flowers were harvested from trees of satsuma, cultivars Kusumoto-wase, Miyamoto-wase,

\footnotetext{
Received for publication 14 Aug. 1989. We thank James W. Cameron for his careful reading of the manuscript. This research was partially supported by Grants-in-Aid for Science Research (61560038) from the Ministry of Education, Science, and Culture of Japan. The cost of publishing this paper was defrayed in part by the payment of page charges. Under postal regulations, this paper therefore must be hereby marked advertisement solely to indicate this fact.
}

Tokumori-wase, Ichifumi-wase, Kanazawawase, Ishizuka-wase, and Sakikubo-wase. These are very early ripening cultivars derived from the Wase (early ripening) satsumas through bud mutation (Iwamasa et al., 1981). Undeveloped seeds $\approx 2 \mathrm{~mm}$ long were dissected aseptically from the fruit and cultured on the medium of Murashige and Tucker (MT) (1969) with a combination of $0.02 \mu \mathrm{M}$ 2,4-D and $0.02 \mu \mathrm{M} \mathrm{BA}$, or $400 \mathrm{mg}$ malt extract (ME)/liter and $185 \mu \mathrm{M}$ adenine. Media were supplemented with $50 \mathrm{~g}$ sucrose/ liter and solidified with $1 \%(\mathrm{w} / \mathrm{v})$ agar $(\mathrm{Ka}-$
Fig. 1. Callus at hypocotyl region of embryos. tayama Chemical Co., Osaka, Japan). The $\mathrm{pH}$ was adjusted to 5.7 before autoclaving at $121 \mathrm{C}$ for $20 \mathrm{~min}$. Cultures were incubated in the dark at $25 \pm 1 \mathrm{C}$.

Somatic embryos developed from cultured seeds of all cultivars on both media 4 months after explanting (Table 1). These embryos were assumed to have arisen from very small nucellar embryos that occur in unfertilized ovules (Wakana and Uemoto, 1988). Frequency of somatic embryo occurrence in seeds was higher on medium with adenine and ME than on that with 2,4-D and BA. Four to 10 somatic embryos emerged from one seed, and in some cultivars more than 10 somatic embryos were formed. In 'Kanazawa-wase' and 'Ishizuka-wase', direct callus initiation was observed from seeds, but the callus became brown and failed to grow.

When somatic embryos were transferred to MT medium with $2.8 \mu \mathrm{M} \mathrm{GA}_{3}$, some embryos callused in the hypocotyl region and did not germinate (Fig. 1). Other somatic embryos developed roots and shoots but produced no callus. The callus was separated from somatic embryos, grown on the same medium, and subcultured twice at 3- to 4week intervals. The callus was friable and its growth was poor. Its appearance resembled that of embryogenic callus obtained from sweet orange (Hidaka and Kajiura, 1988; Kobayashi et al., 1983, 1984; Kochba and Spiegel-Roy, 1977a, 1977b) and Calamondin (Ling et al., 1989). When transferred to a medium with $50 \mathrm{~g}$ lactose/liter and without growth regulators, the callus produced somatic embryos (Fig. 2).

Prevention of browning and vigorous mul-
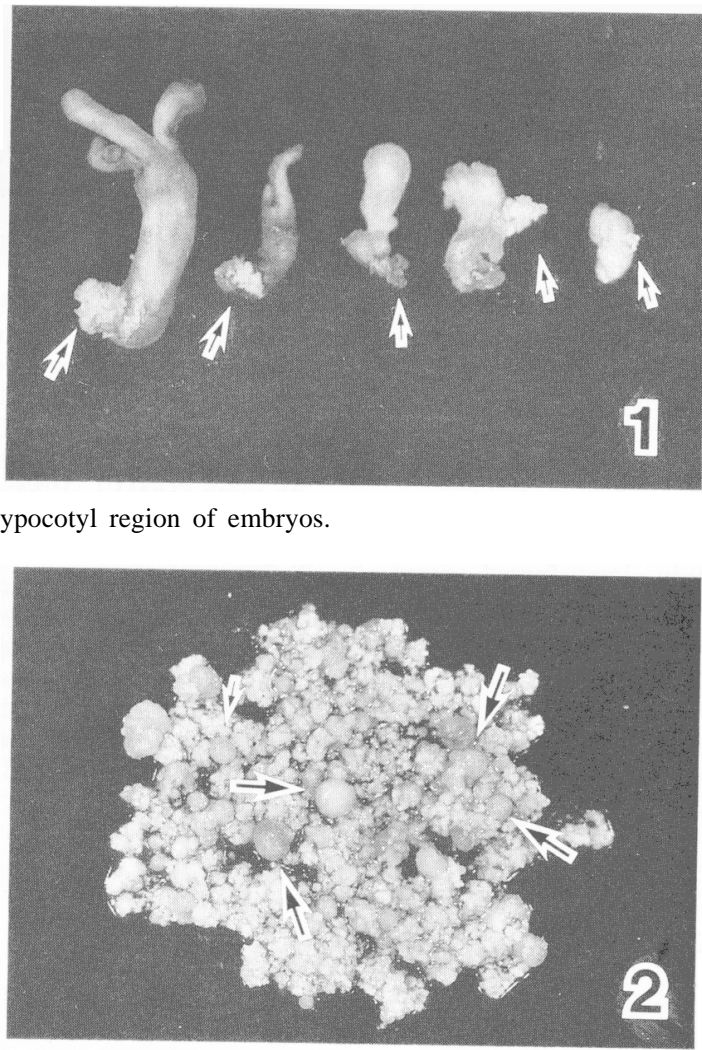

Fig. 2. Embryo formation in callus of 'Ishizuka-wase' 
Table 1. Callus and somatic embryo formation from undeveloped seeds of satsuma cultivaŕs.

\begin{tabular}{|c|c|c|c|c|}
\hline \multirow[b]{3}{*}{ Cultivars } & \multicolumn{2}{|c|}{$\mathrm{MT}+0.02 \mu \mathrm{M} 2,4-\mathrm{D}+0.02 \mu \mathrm{m} \mathrm{BA}$} & \multirow{2}{*}{\multicolumn{2}{|c|}{$\frac{\mathrm{MT}+185 \mu \mathrm{M} \text { adenine }+400 \mathrm{mg} \mathrm{ME} / \mathrm{liter}^{y}}{\text { No. of seeds }}$}} \\
\hline & \multicolumn{2}{|c|}{ No. of seeds } & & \\
\hline & Formed callus & Formed embryoids & Formed callus & Formed embryoids \\
\hline Kusumoto-wase & 0 & 6 & 0 & 14 \\
\hline Miyamoto-wase & 0 & 8 & 0 & 13 \\
\hline Tokumori-wase & 0 & 17 & 0 & 23 \\
\hline Ichifumi-wase & 0 & 15 & 0 & 20 \\
\hline Kanazawa-wase & 0 & 12 & 3 & 16 \\
\hline Ishizuka-wase & 0 & 13 . & 1 & 26 \\
\hline Sakikubo-wase & 0 & 15 & 0 & 24 \\
\hline
\end{tabular}

${ }^{2}$ Fifty seeds were inoculated in each medium for each cultivar.

${ }^{y} \mathrm{MT}=$ Murashige and Tucker medium; $\mathrm{ME}=$ malt extract.

Table 2. Effects of plant growth regulators and gelling agents on callus growth. ${ }^{2}$

\begin{tabular}{|c|c|c|c|c|c|c|}
\hline \multicolumn{5}{|c|}{ Plant growth regulator } & \multirow{2}{*}{\multicolumn{2}{|c|}{ Ratio of callus growth ${ }^{y}$}} \\
\hline \multirow{2}{*}{$\begin{array}{l}2,4-D \\
(\mu \mathrm{M}) \\
\end{array}$} & \multirow{2}{*}{$\begin{array}{c}\mathrm{BA} \\
(\mu \mathrm{M})\end{array}$} & \multirow{2}{*}{$\begin{array}{c}\text { Adenine } \\
(\mu \mathrm{M})\end{array}$} & \multirow{2}{*}{$\begin{array}{c}\mathrm{GA} \\
(\mu \mathrm{M})\end{array}$} & \multirow{2}{*}{$\begin{array}{c}\text { ME } \\
\left(\mathrm{mg} \cdot \text { liter }^{-1}\right)\end{array}$} & & \\
\hline & & & & & Agar & Gelrite \\
\hline -.- & 44.4 & ... & $\ldots$ & -.. & 0.4 & 1.2 \\
\hline --- & 44.4 & --- & $\ldots$ & 400.0 & 0.6 & 1.3 \\
\hline 0.45 & 44.4 & --. & $\ldots$ & --- & 0.2 & 0.2 \\
\hline 0.45 & 44.4 & --. &..- & 400.0 & 0.2 & 0.4 \\
\hline 4.5 & 44.4 & --- & $\ldots$ & -.- & 0.4 & 0.3 \\
\hline 4.5 & 44.4 & --- & -.. & 400.0 & 0.3 & 0.2 \\
\hline -.. & --- & 185.0 . & $\cdots$ & -- & 5.0 & 7.0 \\
\hline$\ldots$ & --- & 185.0 . & -.. & 400.0 & 7.0 & 8.3 \\
\hline$\ldots$ & $\ldots$ & --- & 2.8 & --- & 4.8 & 5.8 \\
\hline -.. & --- & $\cdots$ & 2.8 & 400.0 & 5.4 & 7.0 \\
\hline$\ldots$ & ... & 185.0 & 2.8 & -- & 5.9 & 7.3 \\
\hline$\cdots$ & --- & 185.0 & 2.8 & 400.0 & 6.6 & 11.5 \\
\hline
\end{tabular}

${ }^{2}$ The concentrations of agar and Gelrite were $1 \%$ and $0.2 \%$, respectively.

'Ratio of callus growth was calculated by (Final weight - Initial weight)/initial weight.

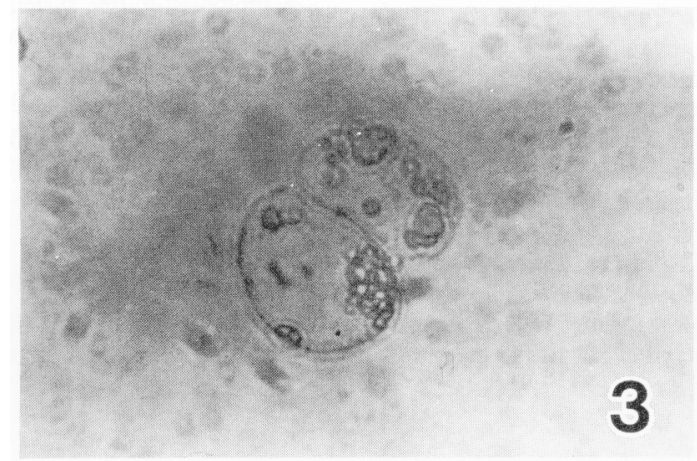

Fig. 3. First protoplasm division $(\times 800)$.

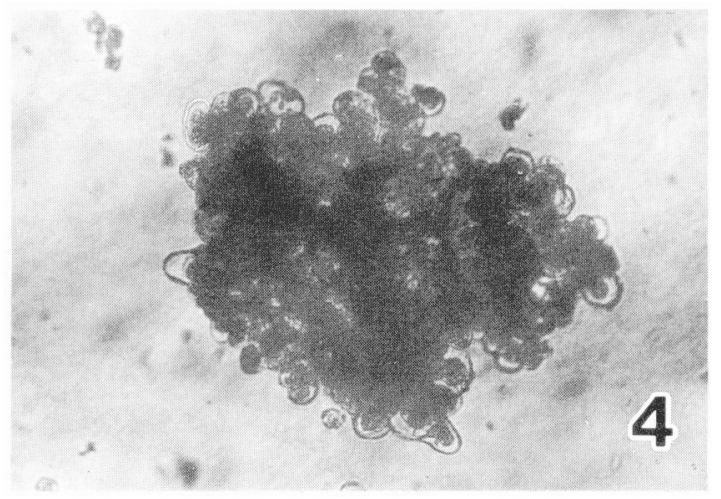

Fig. 4. Colony formation 30 days after plating $(\times 100)$.

triplication were prerequisites for the establishment and maintenance of embryogenic callus. Effects of plant growth regulators and gelling agents on callus growth were exam- ined with the callus of 'Ishizuka-wase'. The combinations of 2,4-D, BA, adenine, $\mathrm{GA}_{3}$, ME, agar, and Gelrite (Kelco Div., Merk \& Co., San Diego, Calif.) were prepared for the screening of suitable media (Table 2). The concentrations of agar and Gelrite were $1 \%(\mathrm{w} / \mathrm{v})$ and $0.2 \%(\mathrm{w} / \mathrm{v})$, respectively. Slow and scant callus proliferation, as well as browning, occurred on media with 2,4-D and/ or BA. Adenine alone or in-combination with $\mathrm{GA}_{3}$ and $\mathrm{ME}$ stimulated callus proliferation. Callus grew best on the medium with 185 $\mu \mathrm{M}$ adenine, $2.8 \mu \mathrm{M} \mathrm{GA}_{3}$, and $400 \mathrm{mg} \mathrm{ME} /$ liter solidified by Gelrite. Vigorous callus growth was also observed on this medium for the other satsuma cultivars.

Embryogenic capacity was retained on this medium over successive subculture, i.e., somatic embryos were formed on these longterm cultured calli following transfer to growth regulator-free medium with $50 \mathrm{~g}$ lactose/liter. In sweet orange, embryogenic callus is maintained for a long period on medium with a high concentration $(44.4 \mu \mathrm{M})$ of BA (Kobayashi et al., 1984) or lacking plant growth substances (Vardi et al., 1982). Conversely, for satsumas, adenine, $\mathrm{GA}_{3}$, and $\mathrm{ME}$ instead of BA were required. Maintenance of embryogenic callus of satsumas depended on the combination of plant growth regulators and Gelrite.

Protoplasts were isolated in a maceration medium of $0.4 \%$ (w/v) Macerozyme R-10 (Yakuruto Pharmaceutical Co., Toyko), 0.2\% (w/v) Cellulase Onozuka R-10 (Yakuruto), $0.1 \%$ (w/v) Driselase (Kyowa Hakko Kogyo Co., Tokyo), half-strength MT medium, and $0, .7 \mathrm{~m}$ sorbitol, according to the methods described by Ling et al.(1989). Typically, yields in the order of $10^{7}$ protoplasts per gram of callus were obtained. Protoplasts were plated on $60 \times 15-\mathrm{mm}$ plastic dishes at a final density of $5 \times 10^{4}$ cells $/ \mathrm{ml}$. The protoplasm culture medium consisted of plant regulatorfree MT medium, $0.3 \mathrm{M}$ sucrose, and $0.3 \mathrm{M}$ sorbitol, solidified with $0.6 \%$ (w/v) Difco Bacto-agar. Cultures were maintained in an incubator at $25 \pm 1 \mathrm{C}$ in darkness.

The first protoplasm division (Fig. 3) and colony formation (Fig. 4) were observed 10 to 14 days and 30 days after incubation, respectively. The plating efficiency at 30 days was $\approx 10 \%$. Green somatic embryos were apparent 60 days after plating and were transferred to MT medium with $50 \mathrm{~g}$ sucrose/liter and $1 \%(\mathrm{w} / \mathrm{v})$ agar, to stimulate rooting and shoot elongation, under 35.3 $\mu \mathrm{mol} \cdot \mathrm{s}^{-1} \cdot \mathrm{m}^{-2}$ light intensity for $16 \mathrm{hr}$ daily, at $25 \pm 1 \mathrm{C}$. At least 20 plantlets were regenerated for each cultivar within 2 months. Plantlets that developed from the somatic 


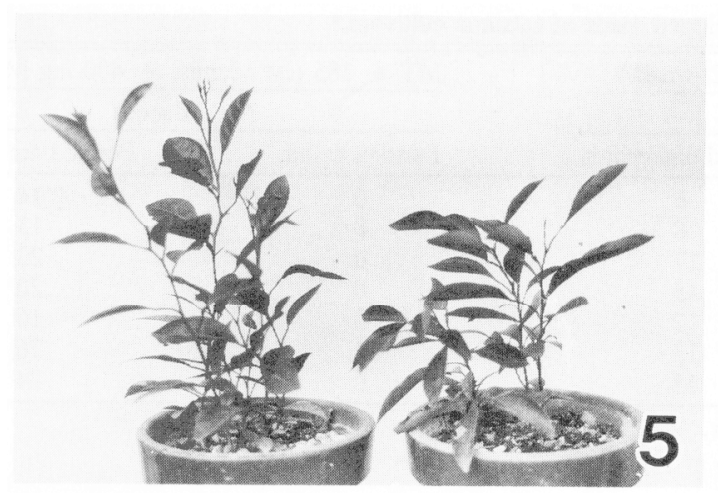

Fig. 5. Plants derived from protoplasts: left 'Ishizuka-wase'; right 'Miyamoto-wase'.

embryos were transplanted to pots in a greenhouse after acclimatization (Fig. 5). Phenotypically, they had a remarkable similarity to nucellar seedling of each cultivar from which the protoplasts were derived.

Embryogenic capacity was maintained through the protoplasts isolated from the callus that was induced from hypocotyl regions of embryos. The full sequence from isolated protoplasts into normal plants in satsuma was achieved by using such embryogenic callus.

Embryogenic callus was established from embryos of undeveloped seed and maintained by this procedure for 14 satsuma cultivars, including the very early, early, midseason, common, and late-ripening types. The protoplasts-from these embryogenic calli will be useful for establishment of somatic hybrids through cell fusion with other citrus protoplasts.

\section{Literature Cited}

Grosser, J. W., F.G. Gmitter, Jr., and J.L. Chandler. 1988a. Intergeneric somatic hybrid plants of Citrus sinensis Cv. Hamlin and Poncirus trifoliata CV. Flying Dragon. Plant Cell Rpt. 7:58.
Grosser, J. W., F.G. Gmitter, Jr. and J.L. Chandler. 1988b. Intergeneric somatic hybrid plants from sexually incompatible woody species: Citrus sinensis and Severinia disticha. Theor. Applied Genet. 75:397-401.

Hidaka, T. and I. Kajiura. 1988. Plantlet differentiation from callus protoplasts induced from Citrus embryo. Scientia Hort. 34:85-92.

Iwamasa, M. 1983. Role of mutation in fruit breeding. Gamma-field Symp. 22:31-48.

Iwamasa, M., N. Nito, S. Yamaguchi, T. Kuriyama, T. Ehara, and T. Nakamuta. 1981, Occurrence of very early mutants from the wase (early ripening) satsumas. Proc. Intl. Soc. Citriculture 1:99-101.

Kobayashi, S. and T. Ohgawara. 1988. Production of somatic hybrid plants through protoplasm fusion in Citrus. J. Agr. Rev. Quart. 22:181188

Kobayashi, S., H. Uchimiya, and I. Ikeda. 1983. Plant regeneration from 'Trovita' orange protoplasts. Jpn. J. Breed. 33:119-122.

Kobayashi, S., I. Ikeda, and M. Nakatani. 1984. Induction of nucellar callus from orange (Citrus sinensis Osb.) ovoles, and uniformity of regenerated plants. Bul. Fruit Tree Rest. Stan. E. 5:43-54.

Kobayashi, S., T. Ohgawara, E. Ohgawara, L Oiyama, and S. Ishii. 1988. Somatic hybrid plan obtained by protoplasm fusion between navel orange (Citrus sinensis) and satsuma mandarin $(C$. unshiu). Plant Cell Tissue Organ Culture 14:6369

Kochba, J. and P. Spiegel-Roy. 1977a. Embryogenesis in gamma-irradiated habituated ovular callus of the 'Shamouti' orange as affected by auxin and by tissue age. Env. Expt. Bet. 17:151159.

Kochba, J. and P. Spiegel-Roy. 1977b. Cell and tissue culture for breeding and developmental studies of Citrus HortScience 12:110-114.

Kochba, J., P. Spiegel-Roy, and H. Safran. 1972. Adventive plants from ovules and nucelli in Citrus. Planta 106:237-245.

Ling, J.T., N. Nito, and M. Iwamasa. 1989. Plant regeneration from protoplasts of Calamondin (Citrus madurensis Lour.). Scientia Hort. 40:325-333.

Murashige, T. and D.P.H. Tucker. 1969. Growth factor requirements of citrus tissue culture. Proc. 1st Intl. Citrus Symp. 3:1155-1161.

Ohgawara, T., S. Kobayashi, E.. Ohgawara, H. Uchimiya, and S. Ishii. 1985. Somatic hybrid plants obtained by protoplasm fusion between Citrus sinensis and Poncirus trifoliata. Theor. Applied Genet. 71:1-4.

Vardi, A., P. Spiegel-Roy, and E. Galun. 1975. Citrus cell culture: isolation of protoplasts, plating densities, effect of mutagenes and regeneration of embryos. Plant Sci. Lett. 4:231-236.

Vardi, A., P. Spiegel-Roy, and E. Galun. 1982. Plant regeneration for Citrus protoplasts: Variability in methodological requirements among cultivars and species. Theor. Applied Genet. 62:171-176.

Vardi, A., D.J. Hutchison, and E. Galun. 1986. A protoplasm-to-tree system in Microcitrus based on protoplasts derived from a sustained embryogenic callus. Plant Cell Rpt. 5:412-414.

Vardi, A., A. Breiman, and E. Galun. 1987. Citrus cybrids: production by donor-recipient protoplast-fosion and verification by mitochondrialDNA restriction profiles. Theor. Applied Genet. 75:51-58.

Wakana, A. and S. Uemoto. 1988. Adventive embryogenesis in Citrus. I. The occurence of adventive embryos without pollination or fertilization. Amer. J. Bet. 74:517-530. 